\title{
Validity and Reliability of a Measuring Device Based on Sound Transmission for Diagnosis of Hip Dysplasia in Newborns
}

\author{
Nicolas Padilla-Raygoza1, Rosalina Diaz-Guerrero', Ma. Laura Ruiz-Paloalto², \\ Teodoro Cordova-Fraga ${ }^{3}$, Modesto Antonio Sosa-Aquino ${ }^{3}$, Aaron Huetzin Perez-Olivas ${ }^{3}$ \\ ${ }^{1}$ Department of Nursing and Obstetrics, Division of Health Sciences and Engineering, Campus Celaya \\ Salvatierra University of Guanajuato, Celaya, Mexico \\ ${ }^{2}$ Department of Clinical Nursing, Division of Health Sciences and Engineering, Campus Celaya Salvatierra \\ University of Guanajuato, Celaya, Mexico \\ ${ }^{3}$ Department of Physical Engineering, Division of Sciences and Engineering, Campus Leon, University of \\ Guanajuato, Leon, Mexico \\ Email: raygosan@ugto.mx
}

Received 19 July 2014; revised 22 August 2014; accepted 16 September 2014

Copyright (C) 2014 by authors and Scientific Research Publishing Inc.

This work is licensed under the Creative Commons Attribution International License (CC BY). http://creativecommons.org/licenses/by/4.0/

(c) (i) Open Access

\section{Abstract}

Sound transmission has been used for diagnosis of hip dysplasia in newborns and infants with tunning fork and sthetoscope. The study aims to identify the validity of a device based on sound transmission. Male and female newborns from Celaya, Gto, ranging from 4 to 28-day-old were selected for the study. The sound transmission device was used both, in bilateral assessment (compared sound transmission) and on each hip separately (sound transmission with extension/flexion). In the first application if the sound is lower by a digit, there is a hip unhealthy. In the second application if the sound is increased by a digit, there is also an alteration of the hip. A hip ultrasound was applied using the Graf technique as a gold standard. Sensitivity, specificity and predictive values were calculated to identify validity. The intra-observer and inter-observer Kappa Test was applied to identify reliability. The hips of 103 newborns were assessed, obtaining a sensitivity of $60.9 \%$, and a specificity of $92 \%$; it should be a positive predictive value of $51.9 \%$ and a negative predictive value of $95 \%$ for the compared sound transmission test. In the sound transmission test with extension/flexion, the values were $82.6 \%, 96.2 \%, 73.1 \%$ and $97.8 \%$ for sensitivity, specificity, positive predictive value and negative predictive value, respectively. The result of the intra-observer kappa was 0.80 and the inter-observer was 0.70 for the compared sound transmission. The intra-observer Kappa was 0.88 and the inter-observer was 0.78 for the compared sound transmission test with extension/flexion. The device for sound transmission is valid and reliable for the diagnosis of dysplastic development hip disease in newborns. 


\section{Keywords}

\section{Validity, Reliability, Sound Transmission, Dysplasia of the Hip}

\section{Introduction}

The developmental dysplasia of hip (DDH) is presumed to be found in 1 out of every 100 newborns in the form of instability and in 1 out of every 1000 newborns in the form of dislocation in the United States [1]. It is also common in Mexico that $1 \%$ of newborns have dysplasic hip disease and $75 \%$ of macrosomic newborns have ultrasonographic evidence of having this impairment, although the evolution to hip dislocation is only reached in a ratio of 1:7000 live births [2].

DDH can develop due to maternal hormones, macrosomy, poor obstetric practices during and after birth, deficient swaddling and carrying of the infant [3]-[5].

Current clinical diagnosis is carried out using traditional maneuvers such as Ortolani, Barlow and Peter-Baden, limited to abduction among others [4]. The disadvantage is that with traditional practices only sub-luxated or dislocated hips may be detected. An early stage of hip dysplasia or an unstable hip may go unnoticed [5].

Fernández [6], mentions that $17 \%$ of affected children are diagnosed by a physician and the rest, $83 \%$ are diagnosed by relatives, usually after the second semester of the infant's life, darkening the prognosis and making treatment more invasive. Early diagnosis and prompt treatment make for an excellent prognosis for hip function. However, if the diagnosis is made late, the prognosis worsens since it can go from an orthopedic to a surgical treatment [3] [4].

For early diagnosis compared sound transmission can be used, as described in 1987 by Stone et al. [7], which allows for detection of unstable hip, sub-luxation or dislocation of the hip using a tuning fork and a stethoscope [5]-[7].

The sound transmission tests are subjective and depend on the hearing capacity of the examiner and the training received [3] [5] [7]. The test shows a sensitivity of $27.27 \%$ and an $86.36 \%$ in the extension/flexion test, superior to the results of 5.11\%, 2.27\% and 5.68\% of Ortolani, Barlow and Peter Baden tests, respectively [5].

The use of the device called bone radar allows for the application of the compared sound transmission test, but graphically and objectively.

This is a device with an acoustic generator; used at a frequency of $256 \mathrm{~Hz}$. It also has a receiver that when it detects sound, it generates a numerical amount on the screen, which is directly related to the power of the sound transmission through the bone being studied [8].

When the pelvic limbs are in extension and adduction sound transmission from femur to symphysis is equal on both sides; when the hip is unstable, subluxated or dislocated, the affected side transmits less sound, since the relationship between the components of the hip is less intimate. When the test is done with hip flexion to $90^{\circ}$, in a healthy hip, the sound remains the same or decreases as the relationship between the components of the joint is less intimate; however, when the hip is unstable, subluxated, or dislocated, transmission of sound increases because the relationship of the components of the hip joint increases.

Our objective was to quantify the validity and reliability of the bone radar device for the diagnosis of DDH in newborns in Celaya, Guanajuato (Gto), Mexico, using the Graf technique of ultrasound as gold standard.

\section{Subjects and Methods}

\subsection{Bioethics Committee}

The protocol was approved by the Research Committee from the Health Sciences and Engineering Division, Universidad de Guanajuato (Celaya-Salvatierra Campus) and by the Bioethics Committee of Celaya's General Hospital belonging to the Ministry of Health for the state of Guanajuato.

\subsection{Study Design}

It is a diagnosis, cross-sectional, based on hospitals study.

The study was conducted on newborns, born in public and private hospitals in Celaya, Guanajuato, Mexico 
from July 2012 to July 2013.

Selected infants: 103.

\subsection{Selection of Participants}

Inclusion criteria:

Male and female newborns between 4 and 28 days old, whose parents agreed to participate in the study through written consent.

Exclusion criteria:

Infants with embryological hip dislocation.

Stratified sampling was performed in hospitals in order to select the participants, $65 \%$ of the participating infants were born in public hospitals in Celaya, Guanajuato, Mexico and 35\% in private hospitals from the same city. Random sampling was performed at each institution, selecting two infants per day.

Sample size:

Hoping that the sound transmission test with extension/flexion using the device has a sensitivity of $90 \%$, the minimum sample size is one impaired hip and 20 healthy hips, with 99\% power and 95\% confidence. (Program for epidemiological analysis of tabulated data. Epidat 3.1, 2006, Xunta de Galicia y Organizacion Panamericana de la Salud).

\subsection{Study Procedures}

During the first stage the objectives of the study were explained to the parents the procedure, they were also provided with a participant's information sheet and any questions on the part of the parents were answered.

Subsequently, they were asked to sign the informed consent form. The compared sound transmission test and the compared sound transmission with extension/flexion test were applied using the device two times by the same researcher and one third time by a different researcher, who were not informed of the other's measurements or results. Then, a hip ultrasound using the Graf technique was applied, as well as static and dynamic tests as the gold standard of diagnosis. The ultrasound specialist did not have access to the clinical evaluation results. The period of time between the sound transmission tests and the hip ultrasound, was 5 minutes.

\subsection{Variables}

\subsubsection{Measuring Exposures}

Data was collected about age, gender, residency, as well as weight and height at birth. Parents were asked about family history of dysplastic hip disease.

The weight was measured using the Sec ${ }^{\circledR}$ baby scale and the height was measured with an infant meter.

The sound transmission test was also applied using the device. With the infant in dorsal decubitus and with pelvic limbs in extension and adduction, the sound generator was placed on the patella and the receiver on the pubis and the amount which appeared on the screen was recorded. If any of the numbers were lower, the hip was considered to be altered.

For the compared sound transmission test with extension/flexion, the infant was placed in dorsal decubitus with pelvic limbs in extension and adduction. The sound generator was placed on the patella and the receiver on the pubis. The quantity that appears on the screen is recorded; then, the hip is flexed to $90^{\circ}$ and the digits on the screen are again recorded maintaining the sound generator on the patella. If the amount on the screen increased, the hip is considered to be altered. If the amount decreases or remains the same the hip is healthy. Subsequently, the test was applied on the other hip in the same way.

The comparative sound transmission test was considered positive if the amount of the sound was one digit lower on one hip than the other. In the extension/flexion test it was considered positive when the amount of the sound was one digit lower with the flexed hip than the extended hip.

\subsubsection{Measuring Results}

Developmental dysplasia of hip, dichotomic qualitative variable, the loss of the relation of the structures of the hip measured with the Graf technique ultrasound with static and dynamic tests measuring $\alpha$ and $\beta$ angles 
[9].

- Healthy Hip-An ultrasound classification at Graf I, where the acetabulum covers $50 \%$ or more of the femoral head; $\alpha>60^{\circ}$ and $\beta>55^{\circ}$.

- Functionally immature hip-ultrasound is rated Graf II; $\alpha 44^{\circ}-59^{\circ}$ and $\beta 55^{\circ}-77^{\circ}$.

- Subdislocation and dislocation-ultrasound classification of Graf III; $\alpha<43^{\circ}$ and $\beta>77^{\circ}$ [9] [10]. Clinical diagnosis alone, has a little value [11].

\subsection{Data Management}

The subjects of the study had no personal identifiers; they were identified using an alpha numeric code. Electronic files of the databases have no personal identifiers.

\subsection{Statistical Analysis}

The sensitivity, specificity, positive predictive value and negative predictive value of the compared sound transmission test and the compared sound transmission with extension/flexion test were calculated with the device using the results of the hip ultrasound with the Graf technique as gold standard. The Intra-observer Kappa (first vs. second measurement) and inter-observer (first vs. third measurement) was also calculated to test the reliability of the device. The statistical analysis was performed using STATA ${ }^{\circledR}$ 13.0. (Stata Corp., College Station, TX, USA).

\section{Results}

The sample was made up by 103 infants whose hips were included in the study, 206 hips were studied.

Table 1 shows the quantitative characteristics of the members of the sample. The average age of the members of the sample was 14 days, which reflects that went to the middle of the first month of age at the moment of participating in the study. The mean birth weight of $3.2 \mathrm{~kg}$ reflects an adequate mean birth weight as well as height of $49.96 \mathrm{~cm}$. An increase of $400 \mathrm{~g}$ between the mean birth weight and the mean at the time of study entry were detected; for height increase between length at birth and height at recruitment was $1.88 \mathrm{~cm}$.

There was a predominance of female infants, with urban residency, without a family history of dysplastic hip development disease (Table 2).

Using the device developed in this work in the compared sound transmission test, 27 impaired hips were detected but only 14 were confirmed with ecography. A number of 179 healthy hips were detected, and 170 were confirmed through ecography (Table 3). Using the test device in the sound transmission compared, the sensitivity was $60.9 \%$, as assessed both hips at the same time and in case of bilateral hip dysplasia, the result will be false negative, because the sound will be equal on both sides and this also results in a low positive predictive value.

Using the device with the extension/flexion test, 26 impaired hips were detected, and 19 were confirmed through ecography; also, 180 healthy hips were detected and 176 were confirmed using the ecography (Table 3). Using the device with the extension / flexion test, each hip was assessed separately, decreasing the false negative and therefore, the specificity and positive predictive value was increased.

Measuring reliability of compared sound transmission test, with Kappa, a good intra-observer reliability ( $\mathrm{K}=$ 0.8 ) and inter-observer $(\mathrm{K}=0.7)$ were found (Table 4$)$.

The reliability is better intra-observer and inter-observer with the extension/flexion test because examines each hip separately (Table 5).

With the ecography, 22 physiologically immature hips, and one subluxation were obtained; 2 cases of immature physiologically hips were bilateral, and 1 more case were subluxation left hip and immature physiologically right hip (Table 6).

\section{Discussion}

The sample of newborns was representative of the population of infants in Celaya, Guanajuato, Mexico, because they were selected from all hospitals in the city.

Only four-day-old and older infants were selected in order to let the body of the newborn stabilize from birth trauma and have fewer false positives.

The use of the device did not cause any discomfort for the infants because vibration is similar to that of a tun- 
Table 1. Quantitatve characteristics of newborns, Celaya, 2013 ( $\mathrm{n}=103)$.

\begin{tabular}{|c|c|c|c|}
\hline \multirow{2}{*}{ Variables } & \multicolumn{3}{|c|}{ Statistics } \\
\hline & Range & Mean & $\mathrm{S}^{\mathrm{a}}$ \\
\hline Age (days) & 4 to 28 & 14.56 & 8.35 \\
\hline Birthweight (kg) & 1.3 to 4.2 & 3.17 & 0.47 \\
\hline Birth high (cm) & 33 to 55 & 49.96 & 2.64 \\
\hline Current weight (kg) & 2.27 to 6.00 & 3.57 & 0.64 \\
\hline Current high $(\mathrm{cm})$ & 47 to 59 & 51.84 & 2.46 \\
\hline
\end{tabular}

${ }^{\text {a }}$ Standard deviation; Source: Forms from the study.

Table 2. Cualitative characteristics of newborns, Celaya, $2013(n=103)$.

\begin{tabular}{|c|c|c|}
\hline \multirow{2}{*}{ Variables } & \multicolumn{2}{|c|}{ Frequencies } \\
\hline & $\mathrm{n}$ & Percent \\
\hline \multicolumn{3}{|l|}{ Gender } \\
\hline Male & 42 & 40.78 \\
\hline Female & 61 & 59.22 \\
\hline \multicolumn{3}{|l|}{ Residency } \\
\hline Urban & 77 & 74.76 \\
\hline Suburban & 16 & 15.53 \\
\hline Rural & 10 & 9.71 \\
\hline \multicolumn{3}{|c|}{ Family history of $\mathrm{DDH}^{\mathrm{a}}$} \\
\hline Yes & 13 & 12.62 \\
\hline No & 90 & 87.38 \\
\hline
\end{tabular}

${ }^{\mathrm{a}} \mathrm{DDH}=$ Developmental dysplasia of hip; Source: Forms from the study.

Table 3. Validity of sound transmission tests using Graf technique ultrasound as gold standard, Celaya, 2013 (n = 206 hips).

\begin{tabular}{|c|c|c|c|c|c|c|}
\hline \multirow[t]{3}{*}{ Sound transmission test } & \multicolumn{6}{|c|}{ Validity } \\
\hline & \multicolumn{2}{|c|}{ Ultrasound } & \multirow{2}{*}{$\begin{array}{l}\text { Sensitivity\% } \\
\text { (95\%CI) }^{\mathrm{a}}\end{array}$} & \multirow{2}{*}{$\begin{array}{l}\text { Specificity\% } \\
(95 \% \mathrm{CI})^{\mathrm{a}}\end{array}$} & \multirow{2}{*}{$\begin{array}{l}\text { Predictive value + } \\
\quad \%(95 \% \mathrm{CI})^{\mathrm{a}}\end{array}$} & \multirow{2}{*}{$\begin{array}{l}\text { Predictive value - } \\
\quad \%(95 \% \mathrm{CI})^{\mathrm{a}}\end{array}$} \\
\hline & Positive & Negative & & & & \\
\hline \multicolumn{7}{|l|}{ Sound transmision } \\
\hline Positive & 14 & 13 & 60.9 & 92.9 & 51.9 & 95.0 \\
\hline Negative & 9 & 170 & (38.8 to 83.0) & (88.9 to 96.9 ) & (31.2 to 72.6 ) & (91.5 to 98.5 ) \\
\hline \multicolumn{7}{|l|}{ Sound transmission $\mathrm{E} / \mathrm{F}^{\mathrm{b}}$} \\
\hline Positive & 19 & 7 & 82.6 & 96.2 & 73.1 & 97.8 \\
\hline Negative & 4 & 176 & (64.9 to 100.0 ) & (93.1 to 99.2 ) & (54.1 to 92.1 ) & (95.4 to 100.0 ) \\
\hline
\end{tabular}

${ }^{\mathrm{a}} 95 \% \mathrm{CI}=95 \%$ confidence interval; ${ }^{\mathrm{b}} \mathrm{E} / \mathrm{F}=$ extension/flexion; Source: Forms from the study.

Table 4. Reliability of compared sound transmission test, Celaya, 2013 ( $\mathrm{n}=206$ hips).

\begin{tabular}{|c|c|c|c|c|}
\hline & \multicolumn{4}{|c|}{ Reliability of compared sound transmission test } \\
\hline & \multicolumn{2}{|c|}{ Second measurement } & \multicolumn{2}{|c|}{ Third measurement } \\
\hline & Positive & Negative & Positive & Negative \\
\hline First measurement & & & & \\
\hline Positive & 24 & 8 & 18 & 9 \\
\hline Negative & 2 & 172 & 4 & 175 \\
\hline Cohen’s Kappa & \multicolumn{2}{|c|}{0.80} & \multicolumn{2}{|c|}{0.70} \\
\hline
\end{tabular}

Source: Forms from study.

Table 5. Reliability of extension/flexion sound transmission test, Celaya, 2013 ( $\mathrm{n}=206$ hips).

\begin{tabular}{ccccr}
\hline & \multicolumn{3}{c}{ Reliability of extension/flexion sound transmission test } \\
\cline { 2 - 5 } & \multicolumn{2}{c}{ Second measurement } & \multicolumn{2}{c}{ Third measurement } \\
\cline { 2 - 6 } & Positive & Negative & Positive & Negative \\
\hline $\begin{array}{c}\text { First measurement } \\
\text { Positive }\end{array}$ & 21 & & 21 & 5 \\
Negative & 0 & 180 & 5 & 0.78 \\
\hline Cohen's Kappa & & 0.88 & & \\
\hline
\end{tabular}

Source: Forms from study. 
Table 6. Ecographic results, Celaya, 2014 ( $\mathrm{n}=206$ hips).

\begin{tabular}{ccc}
\hline Ecography & & Frequencies \\
Graff technique & $\mathrm{n}$ & Percentage \\
\cline { 2 - 3 } Left hip & & 88.35 \\
Healthy & 11 & 10.68 \\
Immature physiologically & 1 & 0.97 \\
Subluxation & & 89.32 \\
Right hip & 92 & 10.68 \\
Healthy & 11 & 0.00 \\
\hline
\end{tabular}

Source: Forms from the study.

ing fork of 256 cycles/second audible sound stimulus. Some infants cried when the sound vibration was applied, but it was attributed to the sensation of perceiving a vibration. In all instances, newborns stopped crying before completing the tests with the device.

One limitation in the study was that we did not detect any case of dislocation and subluxation only one case, so that the device could only be tested in cases of physiological immaturity or subluxation of the hip.

The usual clinical maneuvers, as Ortolani, Barlow, Peter-Baden, Galeazzi, among others, in the clinical diagnosis of developmental dysplasia of the hip, had low sensitivity and positive predictive value, because only detect subluxations or dislocations [5], leaving the physiological immaturity hip undiagnosed and the device detects it.

The validity of the compared sound transmission test was expected to be low (as reported by Padilla, et al. [3]) using a tuning fork and a stethoscope since both hips are assessed at one time and if both hips are affected, it provides a false negative result.

The extension/flexion test studies each hip separately, which produces higher sensitivity and higher positive predictive value, reducing false negatives.

Padilla, et al., [3] [5] obtained similar results using a tuning fork and a stethoscope, with the extension/flexion test with sensitivity, specificity, positive and negative predictive values, similar than the present study.

The reliability of both tests was good, both intra-observer and inter-observer. In previous studies, neither Stone et al. [7] nor Padilla, et al. [3] [5] reported the reliability of sound transmission tests with the tuning fork and stethoscope.

Among the infants enrolled in the study, no cases of hip dislocation were detected, and only one case of subluxated hip and 22 physiological immature hips were diagnosed, but from unhealthy hips, 3 were bilateral.

\section{Conclusions}

The use of the compared sound transmission device is a very good and objective choice for detecting abnormalities of the hip. It does not replace the usual clinical maneuvers, but it complements them and it has the distinction of not including the human factor.

It is considered that the validity and reliability as well as its ease of using, can help to provide early diagnosis of disorders of the hip and avoid a late diagnosis.

\section{Acknowledgements}

The authors thank the Council of Science and Technology of Guanajuato State for the grant GTO-2011-C04164448 for this study and also, Support of Research and Post Grade Office from the University of Guanajuato for its support for this study.

\section{References}

[1] American Academy of Pediatrics. Committee on Quality Improvement, Subcommittee on Developmental Dysplasia of the Hip (2000) Clinical Practice Guideline: Early Detection of Developmental Dysplasia of the Hip. Pediatrics, 105, 896-905. http://dx.doi.org/10.1542/peds.105.4.896

[2] Figueroa-Ferrari, R.C. and Padilla-Raygoza, N. (1994) Congenital Dislocation of the Hip in the Macrosomic Newborn. 
Ultrasound Aspects. Rev. Med. IMSS, 32, 277-279.

[3] Padilla, N. and Figueroa, R.C. (1992) Diagnosis of Congenital Dislocation of the Hip, with the Compared Transmission Test. Rev Mex de Pediatr, 59, 149-151.

[4] Padilla, N. (2013) Developmental Dysplasia of the Hip. In: Martinez, R., Ed., The Health of Children and Adolescent, 8th Edition, El Manual Moderno, Mexico.

[5] Padilla, N. and Figueroa, R.C. (1996) Sound Transmission Tests for the Diagnosis of Congenital Dislocation of the Hip in Newborn. Rev Mex de Pediatr, 63, 265-268.

[6] Fernandez, E. (1989) Congenital Dislocation of the Hip: Reduction with Modified Pavlik’ Braces in Children with One Year Old. Rev Mex Ortop Traumatol, 3, 30-34.

[7] Stone, M., Richardson, J. and Bennet, G. (1987) Another Clinical Test for Congenital Dislocation of the Hip. The Lancet, 1, 954-955. http://dx.doi.org/10.1016/S0140-6736(87)90296-0

[8] Perez, H.A., Cordova, T., Padilla, N. and Sosa, M. (2013) Device to Evoke the Bone System in Hip Dislocation Diagnosis. In: Long, M., Ed., World Congress on Medical Physics and Biomedical Engineering. IFMBE Proceedings, Vol. 39, Elsiever, Beijing, 1386-1388.

[9] Siegel, M.J. (2004) Hip. In: Siegel, M.J., Ed., Pediatrics Ecography, Marban Libros SL, Madrid, 629.

[10] Arti, H., Mehdinasab, S.A. and Arti, S. (2013) Comparing Results of Clinical versus Ultrasonographic Examination in Developmental Dysplasia of Hip. Journal of Research in Medical Sciences, 18, 1051-1055.

[11] Kowalczyk, B., Felus, J. and Kwinta, P. (2005) Developmental Dysplasia of the Hip: The Problems in the Diagnosis Process in Our Own Experience. Medycyna Wieku Rozwojowego, 9, 395-406. 
Scientific Research Publishing (SCIRP) is one of the largest Open Access journal publishers. It is currently publishing more than 200 open access, online, peer-reviewed journals covering a wide range of academic disciplines. SCIRP serves the worldwide academic communities and contributes to the progress and application of science with its publication.

Other selected journals from SCIRP are listed as below. Submit your manuscript to us via either submit@scirp.org or Online Submission Portal.
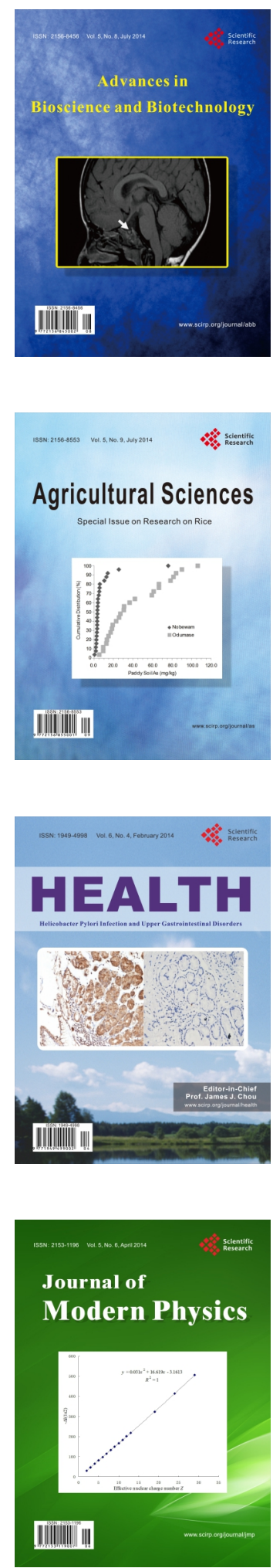
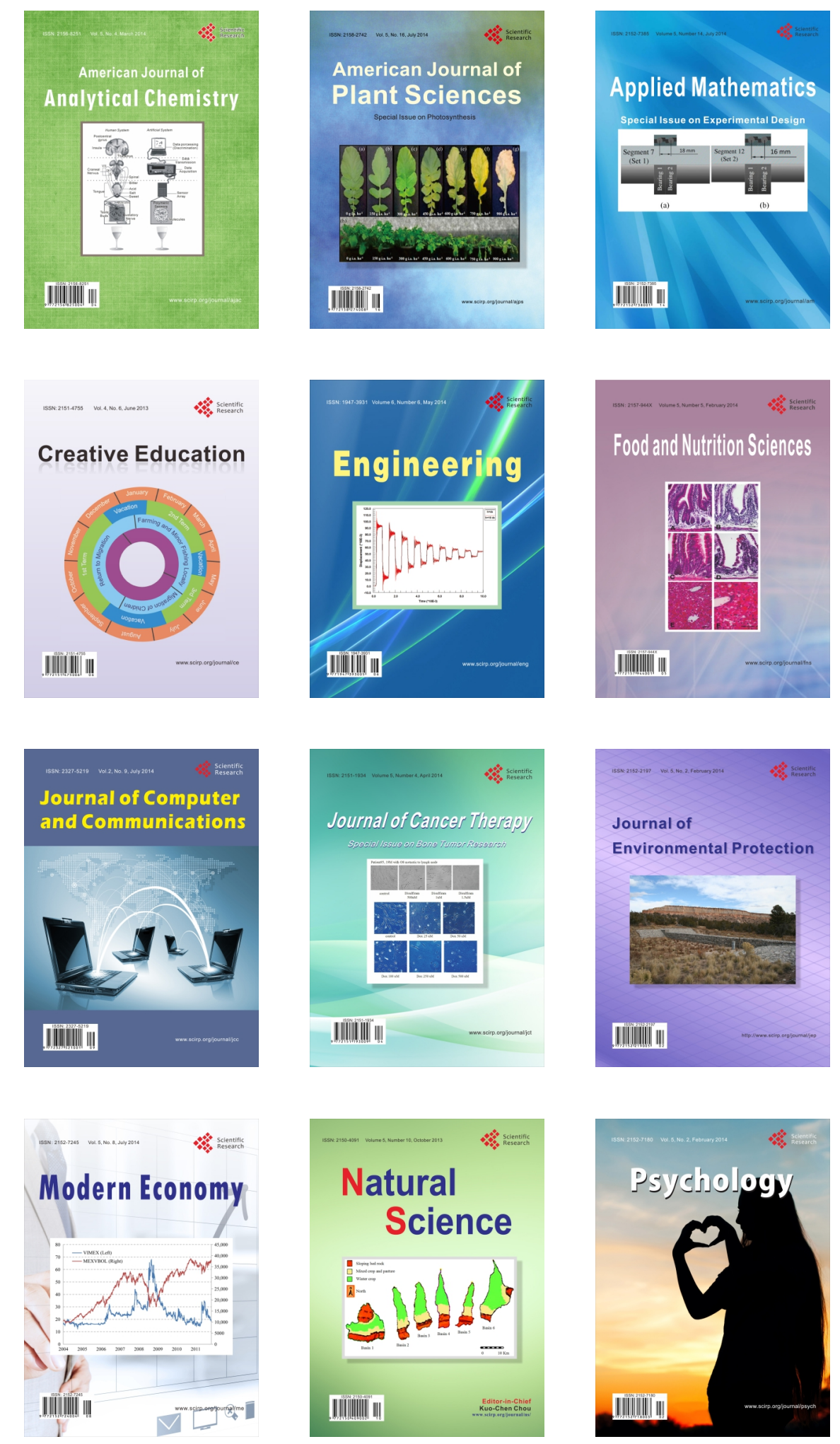